\title{
First record of Fanniidae (Diptera) from New Caledonia
}

\author{
MÁRCIA S. COURI* and VIVIANE R. SOUSA** \\ Departamento de Entomologia, Museu Nacional, Universidade Federal do Rio de Janeiro, \\ Quinta da Boa Vista, s/n, São Cristovão, 20940-040 Rio de Janeiro, RJ, Brazil \\ Manuscript received on December 3, 2018; accepted for publication on March 22, 2019
}

\begin{abstract}
How to cite: COURI MS AND SOUSA VR. 2019. First record of Fanniidae (Diptera) from New Caledonia. An Acad Bras Cienc 91: e20181117. DOI. 10.1590/0001-3765201920181117.

Abstract: The family Fanniidae is newly recorded to New Caledonia. Adult male and female of Fannia capitalis Pont are illustrated as well as the peculiar male terminalia, the female ovipositor, and the egg. Male phallic process and egg are described for the first time.
\end{abstract}

Key words: Diversity, Fannia morphology, new record, Terminalia.

\section{INTRODUCTION}

Fanniidae (Diptera) are a relatively small calyptrate family, with about 330 species in five genera and are represented in all biogeographical regions. The currently known genera and respectively number of species are: Australofannia Pont (one species), Euryomma Stein (19 species), Fannia RobineauDesvoidy (about 300), Piezura Rondani (five species) and Zealandofannia Domínguez \& Pont (2014) (one species).

The family is represented in the AustralasiaOceanian regions by 22 species in four genera (Pont 1989, Domínguez and Pont 2014): Australofannia Pont (one species), Euryomma (one species), Fannia (19 species), and Zealandofannia (one species).

Snyder (1965) presented a study on the Diptera Muscidae of Micronesia, where three species of Fannia were included - F. prisca Stein (in Bonin),

Correspondence to: Márcia Souto Couri

E-mail: courimarcia@gmail.com

*CNPq fellow

**CNPq scholarship

ORCID: https://orcid.org/0000-0002-5340-395X
F. pusio (Wiedemann) (in Palau) and F. leucostica (Meigen) (in Yep). Later, Pont (1977) revised the Australian Fanniidae with keys to segregate the four of the five genera and their species. And recently, Domínguez and Pont (2014) revised the New Zealand species of the family Fanniidae and recognized eleven valid species: Euryomma peregrinum (Meigen), Fannia albitarsis Stein and Fannia canicularis (Linnaeus), all introduced, seven new species of Fannia and a monotypic new genus and species (Zealandofannia mystacina), all endemic to New Zealand.

Adults of Fannia are small to medium-sized and can be recognized by characters of easy visualization as vein Sc evenly bowed towards $C$, without any sinuosity, hind tibia with a sub-median dorsal seta, short and bent vein $\mathrm{A}_{1}+\mathrm{CuA}_{2}$, which imaginary extension intersects an extension of vein $A_{2}$ before the wing margin. Males of many species show differentiated setae on mid femur and tibia, hind femur and the male terminalia is very characteristic, while the female ovipositor has two pairs of spiracles. The morphology of the larvae is also peculiar, with a flattened body and with a 
pair of dorsolateral processes in all segments. For a complete diagnosis see Pont (1977). Males have the interesting behavior to form dancing swarms while females are found in the lower vegetation (Chillcott 1960).

The main propose of the paper is newly record the family from New Caledonia. Male phallic process and egg are described for the first time.

\section{MATERIALS AND METHODS}

The studied material from New Caledonia belongs to the Muséum national d'Histoire naturelle (MNHN, Paris, France). It was collected in 1987 by Lydia Bonnet de Larbogne (L.B.dL.), Jean Chazeau (J.C.), and A. S. Tillier (A.S.T.), as part of the research program "Évolution \& Vicariance en Nouvelle-Calédonie", MNHN, and "Caractérisation faunistique des forêts et maquis non anthopisés", ORSTOM and was loaned to MSC. The terminology follows Cumming and Wood (2017).
The male and female adults were photographed using a Leica M205 C (software version 4.8.0). Male and female terminalia and eggs (found inside female abdomen) were clarified in $\mathrm{KOH} 10 \%$ for 48 hours, immersed in glycerin on blades for dissection. Digital images of the all structures from male and female terminalia and egg were made using an optical microscope with the software Zen 2 (version 2.0).

\section{RESULTS AND DISCUSSION}

The specimens were identified as Fannia capitalis Pont, 1977. This species was originally described from Australian Capital Territory (Black Mountain) and New South Wales and since then, no further reference was made to it.

Pont (1977) gave a detailed description of the species, which has a very small cercal plate and two crossed and strongly sclerotized projections at tip, unique among the genus (Figs. 5 and 9). The species also differs from all other congeners by the

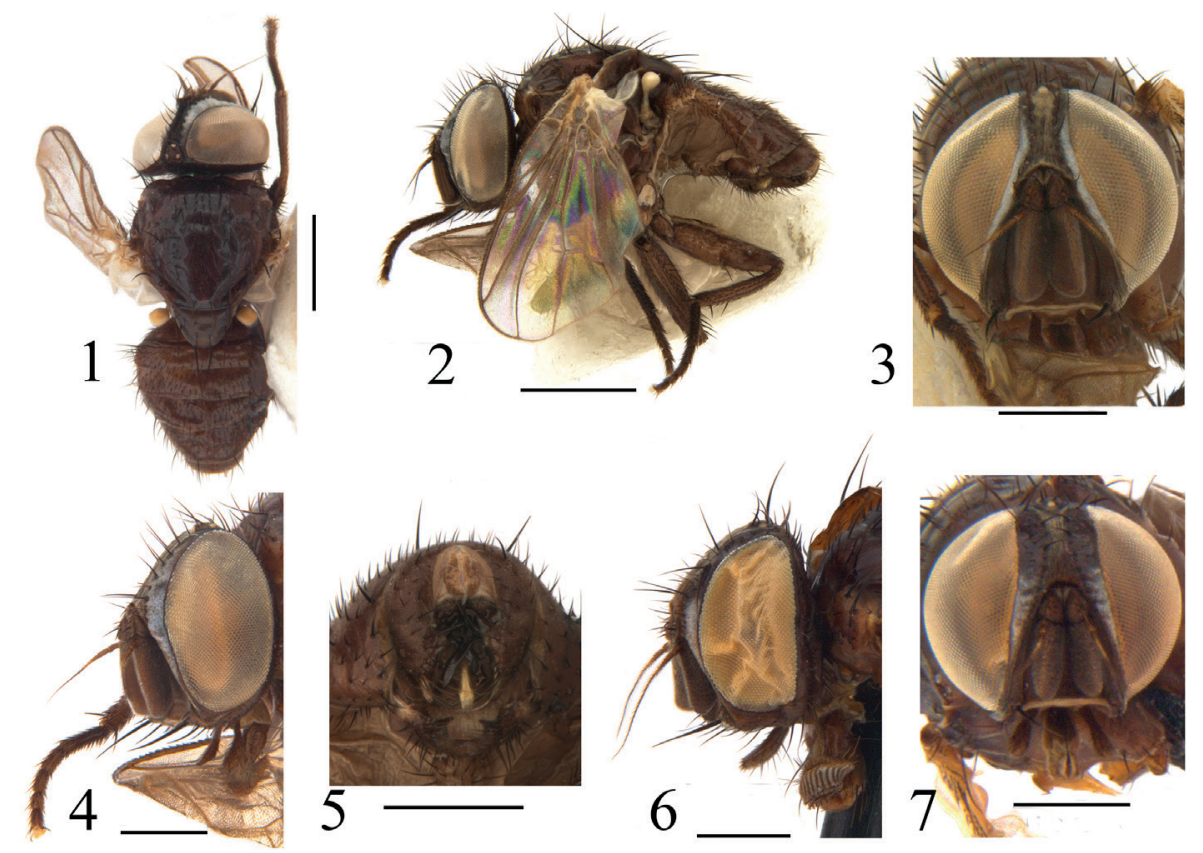

Figures 1-7 - Fannia capitalis Pont 1977: 1. Adult male, dorsal view; 2. Adult male, lateral view; 3. Adult male, head frontal view; 4. Adult male, head lateral view; 5. Adult male, apical portion of abdomen and terminalia, ventral view; 6. Adult female, head frontal view; 7. Adult female, head lateral view. Scale bars $=0.5 \mathrm{~mm}$. 
absence of the submedian dorsal seta on hind tibia. The general color is black shining.

Herein we give detailed images of the male (Figs. 1-5) and female adults (Figs. 6, 7), terminalia of male (Figs. 8-11), ovipositor (Fig. 12), spermathecae (Fig. 13) and also images and descriptions of male phallic process (Figs. 10, 11) and egg (Figs. 14, 15), the two last ones described for the first time.

The original description is here complemented with the morphology of the phallic process and egg.
Male phallic process. Hypandrium short, phallapodeme medium size, distiphallus long, membranous at tip, postgonites large (Figs. 10, 11).

Egg. $(0.75 \mathrm{~mm})$ White, elongated, with lateral flanges in all extension, dorsal surface with a hexagonal pattern. Part of the cephalofaringeal skeleton of the first larval instar can be viewed by transparency (Figs. 14, 15).

Material examined. Nouvelle Caledonie: Rivière Bleue, 310 m, 16640'06”'E 2206’05”S; P5 [forêt sur

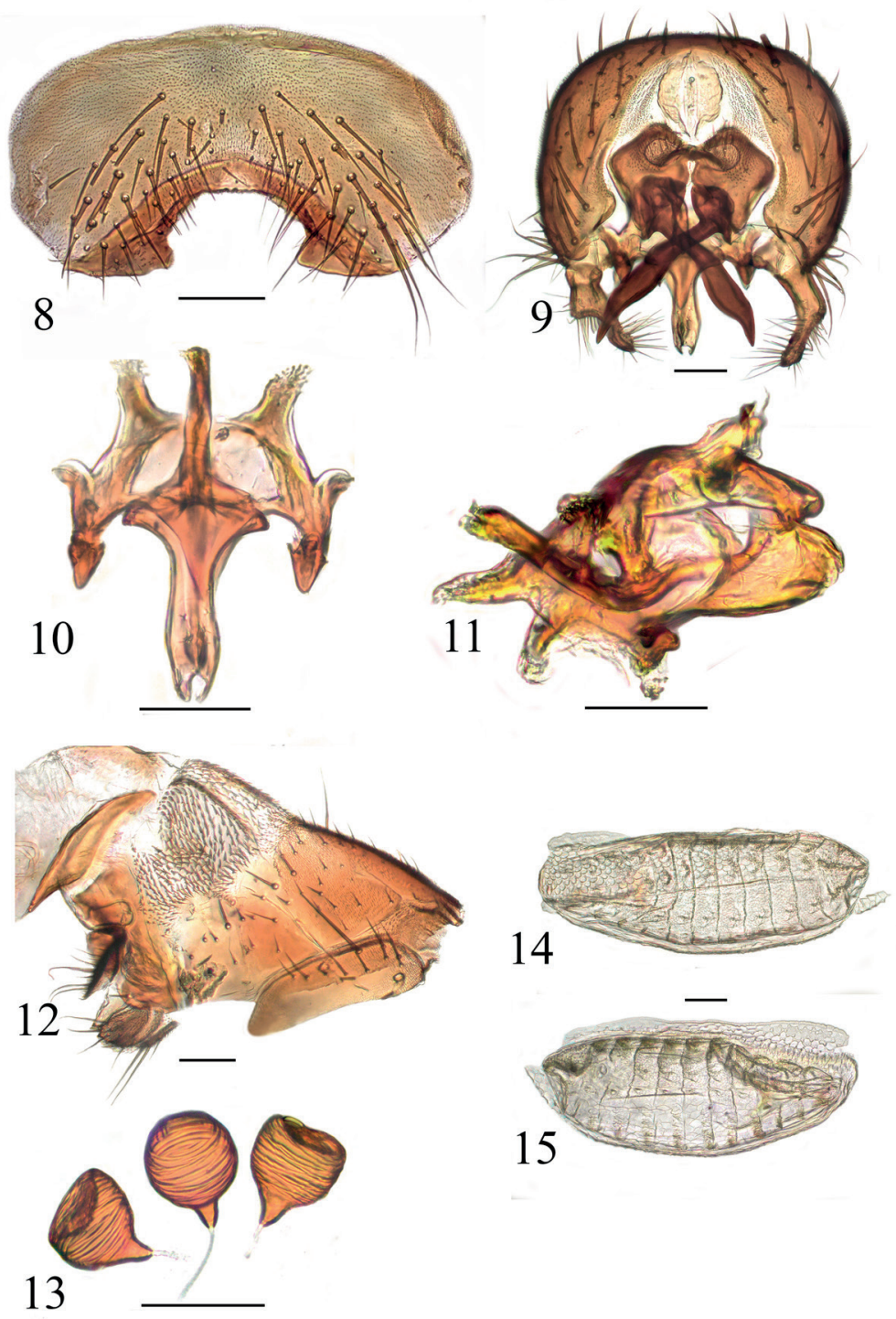

Figures 8-15 - Fannia capitalis Pont 1977: 8. Sternite 5, male, frontal view; 9. Male terminalia, frontal view; 10. Phalic complex, dorsal view; 11. Phalic complex, lateral view; 12. Ovipositor, lateral view, 13. Spermathecae; 14. Egg, dorsal view; 15. Egg, lateral view. Scale bars $=0.1 \mathrm{~mm}$. 


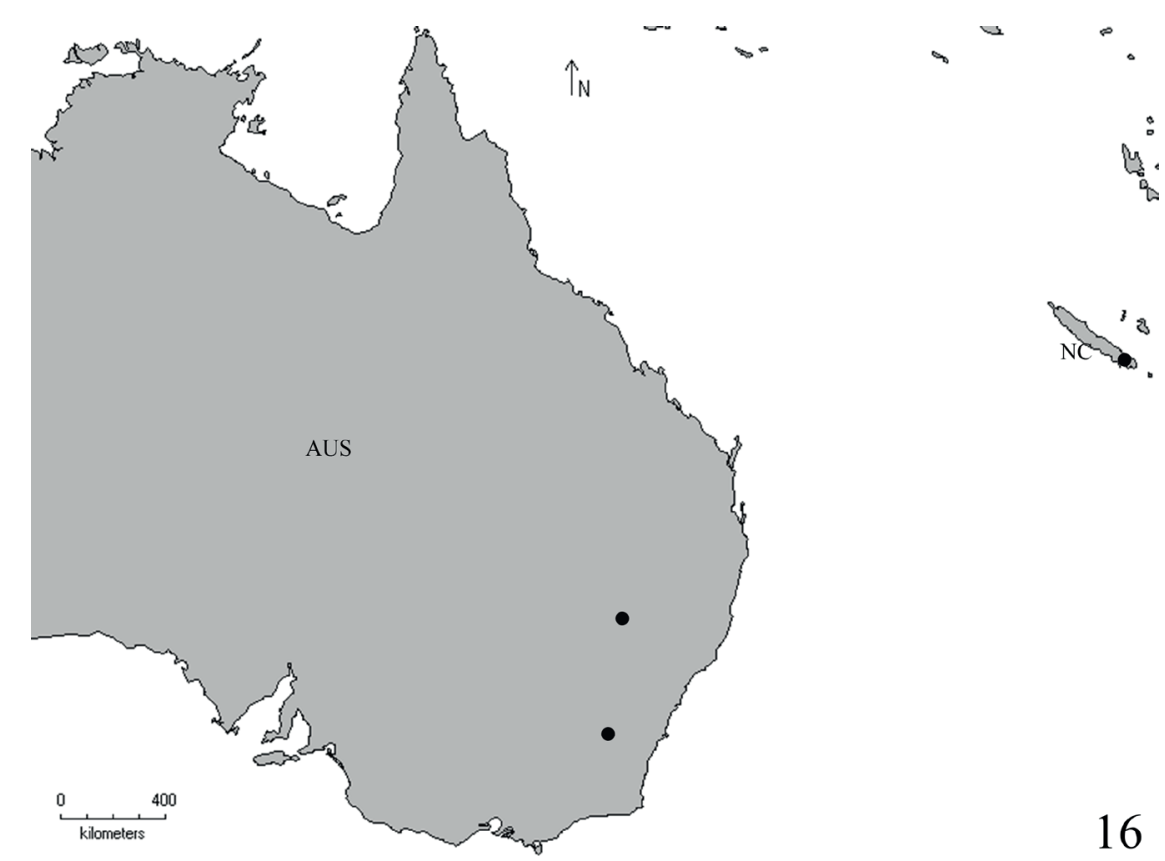

Figure 16 - Map of the known geographical distribution of Fannia capitalis Pont. Legend. AUS = Australia; $\mathrm{NC}=\mathrm{New}$ Caledonia.

alluvions]; 13-16.vi.198; L.B.dL., J.C., A.S.T., 375 a, 4 males, 1 female; 12-25.ii.1987, 377d, 1 male, 1 female.

Geographical distribution: Australia (Australian Capital Territory, Black Mountain) and New South Wales, Goonoo State Forest, 5 miles south of Mendooran) and Nouvelle Caledonie (Rivière Bleue) (Fig. 16).

The new geographical record contributes to the knowledge of the fauna of islands and is relevant for future studies on biogeography and speciation.

\section{ACKNOWLEDGMENTS}

The authors are very grateful to Christophe Daugeron (MNHN) for the loan of the material. We also thank the "Projeto Informatização da Coleção Entomológica do Museu Nacional", Sistema de Informação sobre a Biodiversidade Brasileira (SIBBr)/ Conselho Nacional de Desenvolvimento Científico e Tecnológico $(\mathrm{CNPq})$ (process $\mathrm{nr}$ 405588/2015-1), for the usage of the photography equipment. We thank the anonymous reviewers for the careful reading, comments and suggestions that improved this manuscript.

\section{AUTHOR CONTRIBUTIONS}

MSC: identification and description; VRS: all of images.

\section{REFERENCES}

CHILlCOTT JG. 1960. A revision of the Nearctic species of Fanniinae (Diptera, Muscidae). Can Entomol 92: 5-295.

CUMMING JM AND WOOD DM. 2017. Adult Morphology and Terminology. In: Kirk-Spriggs $\mathrm{AH}$ and Sinclair BJ (Eds), Manual of Afrotropical Diptera, Volume 1. Introductory chapters and keys to Diptera families. Suricata 4. South American National Biodiversity Institute. Pretoria, p. 89-133.

DOMÍNGUEZ MC AND PONT AC. 2014. Fanniidae (Insecta:Diptera). Fauna of New Zealand 71: 91 p.

PONT AC. 1977. A revision of the Australian Fanniidae (Diptera, Calyptrata). Aust J Zool 51: 1-60.

PONT AC. 1989. 108. Family Fanniidae. In: Evenhuis NL (Ed), Catalog of the Diptera of the Australasian and Oceanian Regions. Special Publications of the Bernice Pauahi Bishop Museum, 86, 1155 p. web version. This page last revised 17 April 2016, p. 700-701.

SNYDER FM. 1965. Insects of Micronesia Diptera: Muscidae. Bernice P. Bishop Museum 13: 191-327. 